\title{
Experimental Approach to the Transmission of Information in Hypnosis
}

\author{
Edoardo Casiglia',2, Federica Albertini1,2,3, Valérie Tikhonoff ${ }^{1,2}$, Federica Gasparotti1,2, \\ Jacopo Favaro1, Francesco Finatti1,2, Panagiota Rempelou ${ }^{2,4}$, Antonio Maria Lapenta ${ }^{2}$, \\ Paolo Spinella ${ }^{1}$
}

${ }^{1}$ Department of Medicine, University of Padova, Padova, Italy

${ }^{2}$ Institute Franco Granone, Italian Centre of Clinical and Experimental Hypnosis, Torino, Italy

${ }^{3}$ School of Emergency Medicine, University of Padova, Padova, Italy

${ }^{4}$ Department of Medicine, Hospital of Santorso, Santorso, Italy

Email: edoardo.casiglia@unipd.it

How to cite this paper: Casiglia, E., Albertini, F., Tikhonoff, V., Gasparotti, F., Favaro, J., Finatti, F., Rempelou, P., Lapenta, A. M., \& Spinella, P. (2018). Experimental Approach to the Transmission of Information in Hypnosis. Psychology, 9, 1-13. https://doi.org/10.4236/psych.2018.91001

Received: November 30, 2017

Accepted: January 7, 2018

Published: January 10, 2018

Copyright $\odot 2018$ by authors and Scientific Research Publishing Inc. This work is licensed under the Creative Commons Attribution International License (CC BY 4.0).

http://creativecommons.org/licenses/by/4.0/

\begin{abstract}
The means by which information can be transmitted in hypnosis are debated. Aim of this pilot study was to induce and maintain hypnosis without the hypnotist and the subject being in the same room. In other words, we wanted to clarify, using measurable outcomes, if the hypnotic message could be conveyed through an electronic device. We studied 6 young healthy highly hypnotizable volunteers. After a session aimed at creating the rapport, each participant underwent an experimental session consisting in the execution of a cold pressor test (CTP) in basal awake condition, during hypnotic focused analgesia in the presence of the hypnotist (HFA-P) and during hypnotic focused analgesia suggested via transceiver (HFA-R). Cardiovascular monitoring was performed throughout the session. Perceived pain intensity and hemodynamic parameters during the CPT (baseline, $1^{\text {st }}$ minute, end of the test) in the three phases of the experimental session were compared with paired t-test. During both HFA-P and HFA-R, perceived pain was nullified. The times of permanence in icy water significantly increased in comparison to non-hypnotic condition by $369.2 \%$ in HFA-P and by $394.3 \%$ in HFA-R. The systolic blood pressure $\times$ heart rate product increased in non-hypnotic conditions $\left(+27.8 \%, \mathrm{p}<0.01\right.$, at the $1^{\text {st }}$ minute; $+35.3 \%, \mathrm{p}=0.01$, at the end) but not during HFA-P ( $-1 \%$ and $-0.2 \%$, NS) or HFA-R $(+7.3 \%$ and $-1.6 \%$, NS). In conclusion, hypnosis induced and maintained via transceiver was equivalent to that in the presence of the hypnotist. The hypnotic information therefore turned out to be more important than the means chosen to transmit it.
\end{abstract}

\section{Keywords}

Hypnosis, Information, Communication, Hemodynamics, Rapport 


\section{Introduction}

Hypnosis is becoming more and more employed in clinical practice and in research (Stewart, 2005; Häuser, Hagl, Schmierer, \& Hansen, 2016; Griffiths, 2017; Iserson, 2014). Although self-hypnosis is possible and used, especially in pain control (Beevi, Low, \& Hassan, 2017; Hosseinzadegan, Radfar, Shafiee-Kandjani, \& Sheikh, 2017), it is known that the guide of a hypnotist in a setting of hypnotism allows a deeper and more effective state of trance (Casiglia, 2015).

The role of the hypnotist and the importance of the hypnotist $\leftrightarrow$ subject relationship are not debatable, but the ways and means of communication which can be used to create this relationship or to give effective hypnotic suggestions are still controversial. Is it necessary to be face to face to create the rapport needed by hypnotism or to see its effects? The possibility of transmitting the hypnotic information at distance, by means of an electronic device, has been object of study since the '70s (Stanton, 1978; Roberts, 1978; Gravitz, 1983; Cooperman \& Schafer, 1983; Owens, 1970; Van Nuys, 1977). Though their results were often promising (Stanton, 1978; Owens, 1970; Van Nuys, 1977), these studies were usually lacking in scientific nature, being mainly based on self-reports of efficacy and not supported by objective and measurable data.

An indirect step forward in this field has recently been made by imaging studies, such as those examining neural correlation of the hypnotic state by employing functional magnetic resonance imaging (fMRI) or positron-emission tomography (PET) (Landry, Lifshitz, \& Raz, 2017), in which hypnosis was managed via intercom and headphones (Raz, Fan, \& Posner, 2005; Müller, Bachta, Schrammb, \& Seitza, 2012; Douglas et al., 2014; Demertzi et al., 2011; McGeown, Mazzoni, Vannucci, \& Venneri, 2015).

However, the possibility of inducing (directly or using a post-hypnotic conditioning previously left) plastic monoideism, that is the basis of hypnosis, with unusual means was not the main focus of these studies. The question about the transmission of the information in hypnosis is therefore still open and pressing.

The aim of this pilot study was to clarify whether or not it is plausible to induce and maintain the hypnotic state without the physical presence of a hypnotist in the same room of the participant and in direct, visual contact with him/her. In other words, we wanted to test if the hypnotic message could be conveyed through a device, such as a wireless transmitter-receiver radio.

\section{Methods}

\subsection{Subjects}

Six young, healthy, highly hypnotizable volunteers (highs), whose characteristics are shown in Table 1, were included in this pilot study. All subjects have been defined eligible for hypnosis basing on an interview with the principal investigator, on personal anamnesis and when necessary on Minnesota Multiphasic Personality Inventory (Butcher \& Williams, 1989; Hathaway \& McKinley, 1985); 
Table 1. General characteristics of the participants of the study.

\begin{tabular}{cc}
\hline Characteristic & Mean \pm standard deviation \\
\hline Age (years) & $26.0 \pm 4.3$ \\
Sex (M/F) & $2(33.3 \%) / 4(66.7 \%)$ \\
Education (years of schooling) & $19.5 \pm 2.7$ \\
Weight $(\mathrm{kg})$ & $63.0 \pm 9.0$ \\
Height $(\mathrm{cm})$ & $172.2 \pm 8.0$ \\
Systolic blood pressure ${ }^{*}(\mathrm{mmHg})$ & $125.8 \pm 15.4$ \\
Diastolic blood pressure ${ }^{*}(\mathrm{mmHg})$ & $76.3 \pm 6.2$ \\
Heart rate ${ }^{*}(\mathrm{bpm})$ & $66.7 \pm 14.3$ \\
Stroke volume ${ }^{*}(\mathrm{ml})$ & $81.5 \pm 20.0$ \\
Cardiac output ${ }^{*}\left(1 \times \mathrm{min}^{-1}\right)$ & $5.1 \pm 1.1$ \\
\hline
\end{tabular}

Note: ${ }^{\star}$ Cardiovascular parameters are measured in basal conditions, after resting in supine position until reaching hemodynamic stability.

this screening allowed to exclude subjects more prone to develop unwanted effects following hypnotic dissociation. Hypnotizability was ascertained through the Italian version of the Harvard Group Scale of Hypnotic Susceptibility, Form A (De Pascalis, Russo, \& Marrucci, 2000; Shor \& Orne, 1963). All subjects were classified as highs.

\subsection{Ethics}

The study was approved by the Ethics Committee of the University Hospital of Padua and was conducted according to the principles of the Declaration of Helsinki for Human Research (41 ${ }^{\mathrm{s}}$ Medical Assembly, 1990). Every subject was previously and individually informed in an appropriate place and with necessary time about the purpose, the execution and the possible risks of the procedure. The subjects were free to ask all questions for a complete comprehension of the procedure. All participants gave valid informed consent and signed a form according to the Italian Law 675/1996 and to the Law of the Veneto Region $34 / 2007$.

\subsection{Preliminary Session}

Each subject underwent a preliminary session in order to establish a valid interpersonal rapport between the operator and the subject himself. Subjects were guided through verbal suggestions to focus on a single idea, excluding any other internal or external stimulus. Signals such as the closing of the eyes, the relaxation of facial muscles, the lower jaw dropping and the slower breathing (Granone, 1972) allowed the hypnotist to verify the hypnotic state and to maintain it with appropriate suggestions. Although no post-hypnotic conditioning of induction was left, this procedure allowed to reach a faster and more effective plastic monoideism during the experimental session. 


\subsection{Experimental Session}

Protocol. As usual in our Laboratory of Experimental Hypnosis at the University of Padua (Casiglia et al., 1997, 2006, 2007, 2010, 2012a, 2012b, 2015, 2016; Facco, Casiglia, Masiero, Tikhonoff, Giacomello \& Zanette, 2011; Giordano, Tikhonoff, Tosello, Lapenta, \& Casiglia, 2012; Tikhonoff et al., 2012; Tikhonoff, Senzolo, Lapenta, Palatini, \& Casiglia, 2017), in designing the protocol, specific attention was paid to using standardized instruments commonly employed in physiology and cardiology in order to make the study repeatable. As previously demonstrated both by our Laboratory (Casiglia et al., 2007, 2015, 2016; Facco et al., 2011) and by other research groups (Sharav \& Tal, 2004; Chaves \& Dworkin, 1997), hypnotic focused analgesia (HFA) prevents pain in a real, measurable and repeatable way, also reducing or even abolishing the reflex autonomic response to pain. We induced ischemic pain by immersing the participant's hand in icy water at $0^{\circ} \mathrm{C}$ temperature (a procedure called cold pressor test, CPT, used by cardiologists in the study of the coronary reserve) (Mitchell, MacDonald, \& Brodie, 2004; Peckerman et al., 1998; Sevre \& Rostrup, 1999). As previously done (Casiglia et al., 2007, 2015, 2016), the pain accompanying CPT and its cardiovascular consequences were used as markers to judge the realization and the degree of HFA both in presence of the hypnotist and with the use of the radio device.

The experimental session, which took place a few days after the preliminary one, consisted in three distinct phases (described in detail below) performed in a randomized order to minimize any possible residual effect of previous methods of induction on the following phases. Figure 1 shows the experimental setting.

Basal non-hypnotic condition CPT. In this phase, participants lay down for at least 15 minutes, relaxed, until reaching hemodynamic stability, and then were asked to place their left hand in icy water. Local ischemic pain evoked by this maneuver is usually tolerated for a few minutes and is accompanied by

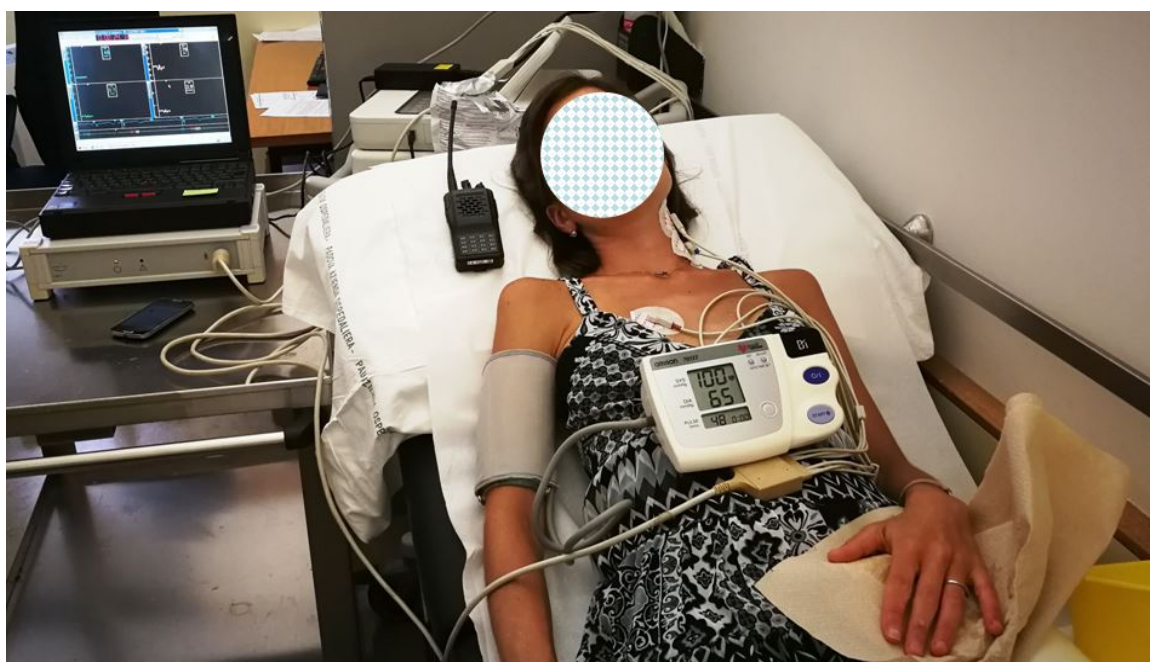

Figure 1. Setting in which the experimental session took place. 
changes in blood pressure, heart rate and cardiac output due to the reflex cardiovascular response to pain (Sevre \& Rostrup, 1999).

Subjects were free to interrupt the procedure by taking their hand out of the water whenever (and only when) they judged pain unbearable.

Hemodynamic and pain monitoring during all the stages of the test will be better discussed in the next paragraphs.

HFA in the presence of the hypnotist (HFA-P). For this step of the procedure, the participants received rapid hypnotic induction and deepening through verbal suggestions by an expert hypnotist. Once the hypnotic trance was reached, HFA was suggested. In particular, according to our previous experience (Casiglia et al., 2016), we used for this purpose the body dysmorphism technique, suggesting that the left forearm and hand have been temporarily detached from the body and placed on a table to be operated on. When the participant was ready, the CPT was performed with the usual operating methods. At the end of the test, body representation was restored and the participant was de-hypnotized.

HFA via radio transceiver (HFA-R). During this phase the hypnotist left the room where the test was being performed to stay in a room nearby. Another expert operator stayed in the room to supervise the procedure and the cardiovascular monitoring and for safety reasons, but did not interfere with hypnosis in any way. Hypnotic induction, deepening and body dysmorphism were obtained with verbal suggestions given to the subjects using a couple of transmitter-receiver Radio Mobile VX-246 Vertex Standard LMR EMEA Co. LTD (Yaesu, Cypress, CA, USA) with Ni-Cd FVB-64 AAA46X (DC 7.2 V, $700 \mathrm{~mA}$ ) battery pack. The hypnotist and the participant were able to communicate throughout the test only using these devices.

The CPT was performed with the same procedure described above. At the end of the test, the restoration of body representation and the de-hypnotization were performed via two-way radio as well.

Hemodynamic monitoring. Systolic and diastolic blood pressure measurements (in $\mathrm{mmHg}$ ) were taken at the right upper arm with a validated automated oscillometric device (705 IT, Omron, Hoofddorp, The Netherlands). Pulse pressure $(\mathrm{mmHg})$ was calculated as systolic-diastolic blood pressure, and mean blood pressure (in $\mathrm{mmHg}$ ) as diastolic $+1 / 3$ pulse pressure. Body surface area was calculated as $\left(\right.$ weight $t^{0.425} \times$ height $\left.t^{0.725}\right) \times 0.007184$ (Du Bois \& Du Bois, 1926).

Stroke volume (in $\mathrm{ml}$ ) was measured through thoracic electrical bioimpedance using PhysioFlow Lab1 ${ }^{\mathrm{TM}}$ (Manatec Biomedical, Ebersviller, France) featuring signal morphology analysis; the same device provided heart rate measurement (in bpm) from RR intervals. Cardiac output (in $1 \times \mathrm{min}^{-1}$ ) was automatically calculated by the PhysioFlow from stroke volume $\mathrm{x}$ heart rate. Cardiac index (in $1 \times \min ^{-1} \times \mathrm{m}^{-2}$ ) was also calculated.

Double product (in bpm $\times \mathrm{mmHg}$ ), a well-known index of cardiac workload (White, 1999; IDACO Investigators, 2013), was calculated for each moment as 
the product of systolic blood pressure $\mathrm{x}$ heart rate.

Cardiovascular measurements were taken before starting the CPT, after 1 minute of immersion of the hand in icy water, at the end of the test (when the ischemic pain was perceived as unbearable), and after the subject reached the basal condition again.

Pain assessment. Subjective experience of pain was quantified through the use of the Numeric Rating Scale (NRS-11). Subjects were asked to give a score of pain intensity on a scale ranging from 0 (no pain) to 10 (worst pain ever) after 1 minute of CPT, and then to rate it again at the end of the test (when the ischemic pain was not tolerable anymore and the hand was taken out of the water).

We waited for the pain to get back to 0 before moving forward to the following steps of the experimental procedure.

Objective pain tolerance was expressed by the duration of the immersion of the hand in icy water (in seconds).

\subsection{Statistics}

Continuous variables were expressed as mean \pm standard deviation. Cardiovascular parameters measured during the test (before starting the CPT, after 1 minute of immersion of the hand in icy water and at the end of the test) during the three phases of the experimental procedure (non-hypnotic conditions, HFA-P and HFA-R) were compared with paired t-test. The null hypothesis was rejected for a probability $<0.05$.

\section{Results}

\subsection{Subjective Experience and Perception of Pain}

Figure 2 shows perceived pain on NRS-11 scale after 1 minute of CPT and at the end of the test (highest tolerable pain) during the three phases of the experiment. HFA, both in the presence of the hypnotist and via radio, abolished pain perception in all subjects.

Subjects tolerated well the presence and use of the transceiver and showed no discomfort for the absence of the hypnotist from the room where the experiment took place.

\subsection{Pain Tolerance}

Times of permanence of the hand in icy water are shown in Figure 3 and express ischemic pain tolerance. Mean time of permanence in non-hypnotic conditions was $166.8 \pm 100.8$ seconds and increased significantly both during HFA-P ( $615.8 \pm 76.8$ seconds, $+369.2 \%, p<0.05$ compared to non-hypnotic condition) and during HFA-R $(657.7 \pm 19.1$ seconds, $+394.3 \%, p<0.05)$; there was no significant difference between the times obtained with the two procedures.

During HFA-P, the CPT was interrupted only once at the express request of subject No. 4 who, despite being totally analgesic, expressed the desire to reunite with his arm, from which she had been separated by the suggestion of dysmorphism 


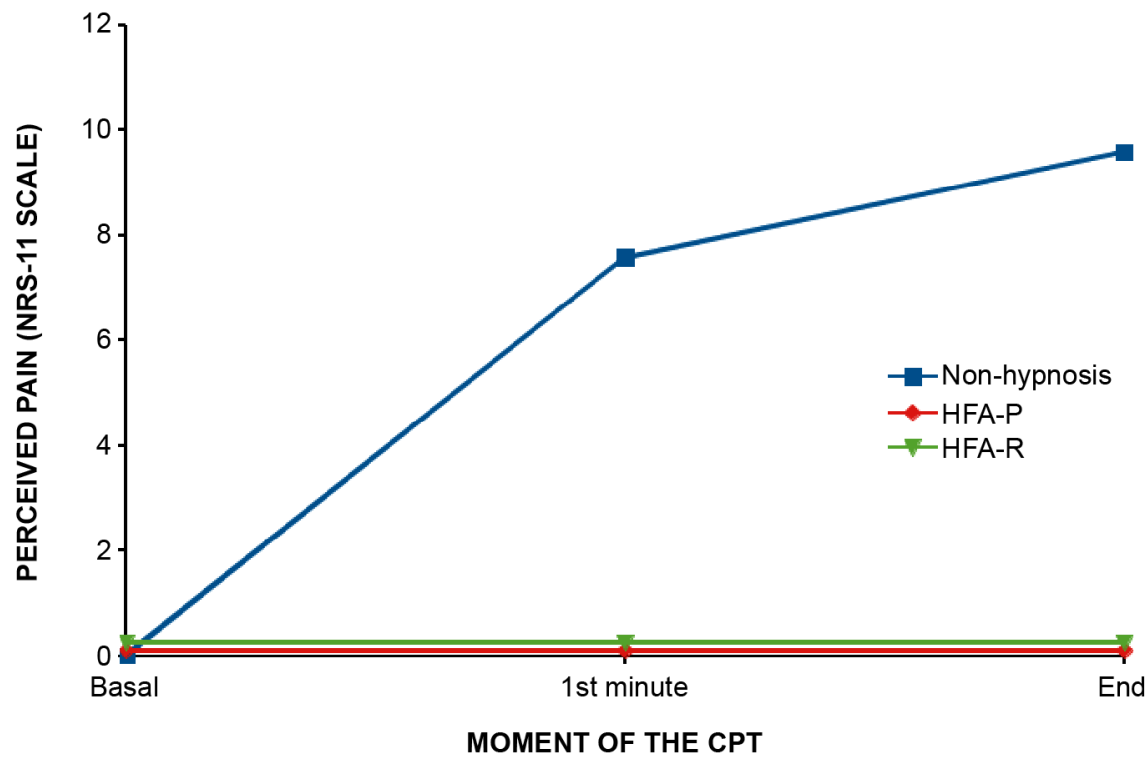

Figure 2. Perceived pain before the start of the CPT, after 1 minute of immersion of the left hand in icy water and at the end of the test in the three phases of the experimental session.
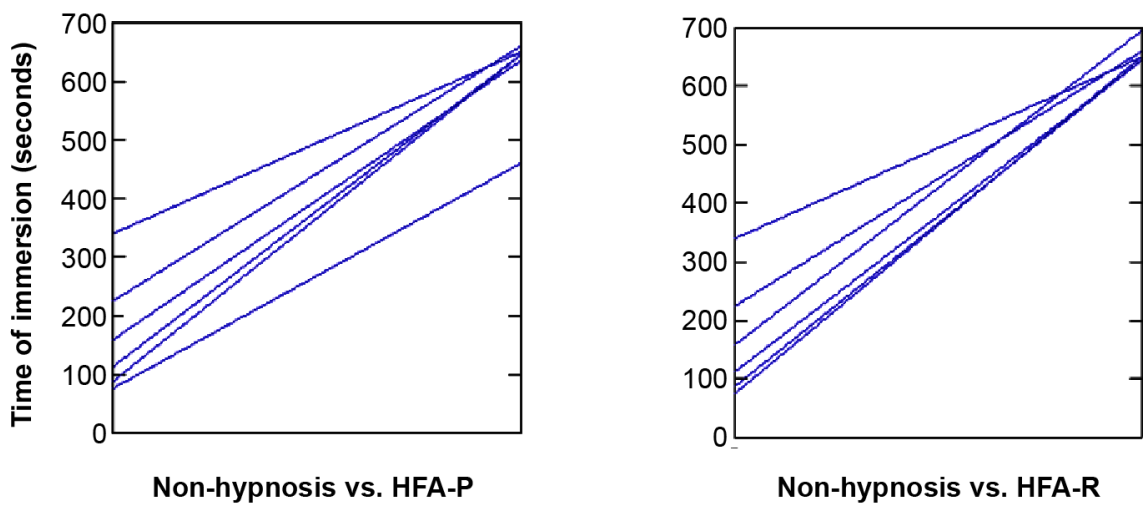

Figure 3. Times of immersion of the hand in icy water during HFA-P (left panel) and during HFA-R (right panel) compared to that in non-hypnotic conditions. Each line represents a participant.

("My arm is calling me"). In all the other cases, the final hemodynamic measurements and the procedures to stop the test started arbitrarily after 10 minutes of immersion, as previously planned in the protocol. Longer times of immersion were not relevant to the aim of this study and presented a risk of freezing-though very little.

\subsection{Objective Evaluation of Hemodynamic Consequences of Pain}

Effect of the CPT. Hemodynamic parameters measured in basal condition and during CPT in the three phases of the experiment are reported in Table 2.

As expected, in non-hypnotic conditions the hemodynamic reflex response to the ischemic pain provoked by the CPT led to an increase in diastolic blood pressure, mean blood pressure and heart rate (Table 2). Double product was 
Table 2. Hemodynamic parameters (expressed as mean \pm standard deviation) at baseline and during the execution of the CPT in the three phases of the experimental session (non-hypnotic conditions, hypnotic focused analgesia in the presence of the hypnotist, HFA-P, and hypnotic focused analgesia via radio, HFA-R).

\begin{tabular}{|c|c|c|c|}
\hline Parameter & Baseline & $1^{\text {st }}$ minute of CPT & End of CPT \\
\hline & \multicolumn{3}{|c|}{ Non-hypnosis (usual consciousness) } \\
\hline Systolic blood pressure (mmHg) & $125.8 \pm 15.4$ & $139.7 \pm 17.6$ & $138.3 \pm 20.6$ \\
\hline Diastolic blood pressure ( $\mathrm{mmHg})$ & $76.3 \pm 6.2$ & $90.7 \pm 7.4^{*}$ & $86.8 \pm 9.1^{*}$ \\
\hline Mean blood pressure (mmHg) & $92.8 \pm 8.3$ & $107.0 \pm 9.8^{*}$ & $104.0 \pm 11.4^{*}$ \\
\hline Heart rate $(\mathrm{bpm})$ & $66.7 \pm 14.3$ & $76.8 \pm 18.8$ & $82.3 \pm 20.2^{*}$ \\
\hline Stroke volume (ml) & $81.5 \pm 20.0$ & $79.5 \pm 21.2$ & $79.7 \pm 21.4$ \\
\hline Cardiac output $\left(1 \times \min ^{-1}\right)$ & $5.1 \pm 1.1$ & $5.8 \pm 1.1$ & $6.0 \pm 1.2$ \\
\hline \multirow[t]{2}{*}{ Cardiac index $\left(1 \times \min ^{-1} \times \mathrm{m}^{-2}\right)$} & $2.9+.0 .5$ & $3.3+0.6$ & $3.4 \pm 0.6$ \\
\hline & \multicolumn{3}{|c|}{ HFA-P } \\
\hline Systolic blood pressure (mmHg) & $129.7 \pm 18.5$ & $134.0 \pm 16.9$ & $134.0 \pm 15.6$ \\
\hline Diastolic blood pressure (mmHg) & $72.8 \pm 17.1$ & $82.2 \pm 7.5$ & $84.2 \pm 6.4$ \\
\hline Mean blood pressure (mmHg) & $91.8 \pm 13.0$ & $99.4 \pm 9.8$ & $100.8 \pm 9.0$ \\
\hline Heart rate $(\mathrm{bpm})$ & $73.0 \pm 17.8$ & $69.3 \pm 16.8$ & $69.3 \pm 15.6$ \\
\hline Stroke volume (ml) & $81.8 \pm 21.1$ & $80.0 \pm 19.9$ & $78.0 \pm 20.6$ \\
\hline Cardiac output $\left(1 \times \mathrm{min}^{-1}\right)$ & $5.8 \pm 1.3$ & $5.4 \pm 1.2$ & $5.3 \pm 1.0$ \\
\hline \multirow[t]{2}{*}{ Cardiac index $\left(1 \times \min ^{-1} \times \mathrm{m}^{-2}\right)$} & $3.3 \pm 0.6$ & $3.0 \pm 0.6$ & $3.0 \pm 0.5$ \\
\hline & \multicolumn{3}{|c|}{ HFA-R } \\
\hline Systolic blood pressure (mmHg) & $126.3 \pm 16.9$ & $134.0 \pm 18.9$ & $129.7 \pm 16.5$ \\
\hline Diastolic blood pressure (mmHg) & $79.8 \pm 9.7$ & $82.5 \pm 8.9$ & $79.2 \pm 5.8$ \\
\hline Mean blood pressure $(\mathrm{mmHg})$ & $95.3 \pm 10.8$ & $99.7 \pm 11.1$ & $96.0 \pm 8.0$ \\
\hline Heart rate $(\mathrm{bpm})$ & $70.7 \pm 15.4$ & $71.8 \pm 17.6$ & $67.3 \pm 14.4$ \\
\hline Stroke volume (ml) & $74.2 \pm 27.4$ & $76.2 \pm 27.3$ & $77.0 \pm 21.1$ \\
\hline Cardiac output $\left(1 \times \min ^{-1}\right)$ & $4.8 \pm 1.1$ & $5.1 \pm 1.0$ & $5.0 \pm 0.7$ \\
\hline Cardiac index $\left(1 \times \min ^{-1} \times \mathrm{m}^{-2}\right)$ & $2.8 \pm 0.5$ & $2.9 \pm 0.6$ & $2.9 \pm 0.3$ \\
\hline
\end{tabular}

Note: ${ }^{*} p<0.05$ compared to the baseline.

significantly higher after 1 minute $(+27.8 \%, p<0.01)$ and at the end of the test $(+35.3 \%, p=0.01)$ than in basal condition (Figure 4). During HFA-P and HFA-R there was no significant variation of double product during the CPT in comparison to the baseline (Figure 4).

Comparison between phases. Double product at the $1^{\text {st }}$ minute of the test was significantly lower both during HFA-P $(9443.5 \pm 3213.4 \mathrm{bpm} \times \mathrm{mmHg})$ and in HFA-R $(9768.2 \pm 3365.0 \mathrm{bpm} \times \mathrm{mmHg})$ than in non-hypnosis $(10858.3 \pm$ $3564.0 \mathrm{bpm} \times \mathrm{mmHg})$; the same happened at the end of the test $(9375.5 \pm 2780.4$ and $8792.3 \pm 2602.3 \mathrm{mmHg}$, respectively, vs. $11560.5 \pm 4175.5 \mathrm{mmHg}$ ). On the 


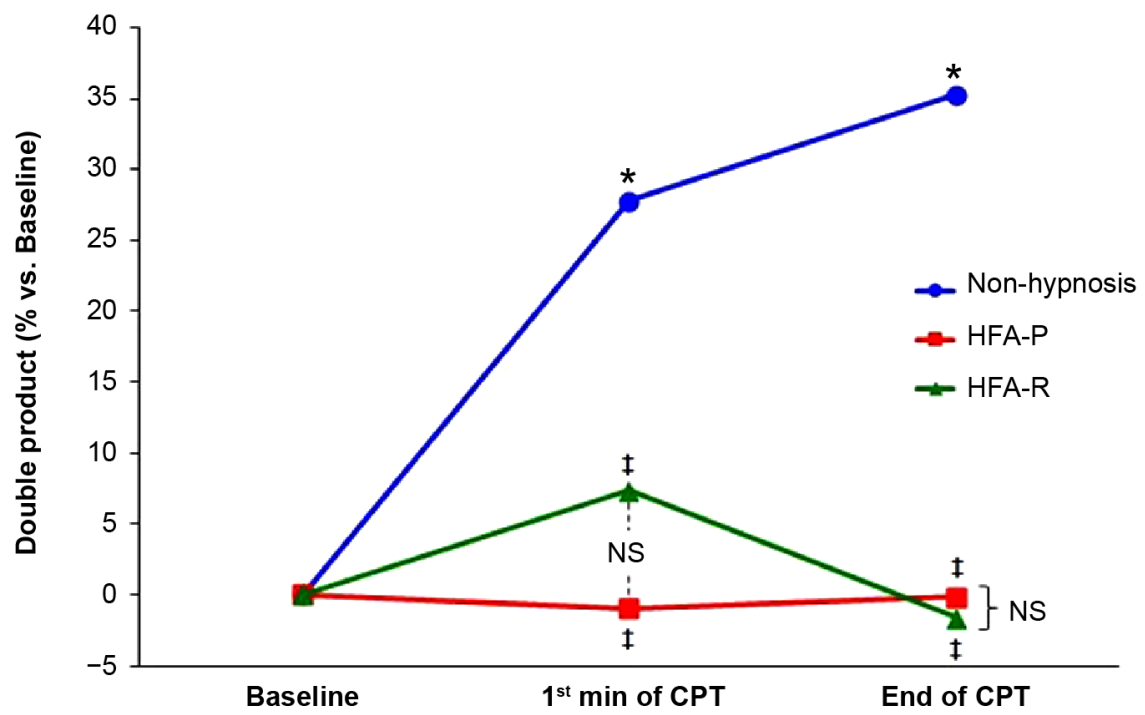

Figure 4. Double product (systolic blood pressure $\times$ heart rate) during the CPT in the three phases of the experimental session. ${ }^{\star} p<0.05$ vs. baseline; ${ }^{\ddagger} p<0.05$ vs. the corresponding moment of the CPT in basal awake condition.

contrary, double product values did not differ significantly between the two hypnotic techniques at any moment of the test (Figure 4).

\section{Discussion}

Hypnotic induction and management usually covers the whole spectrum of communication: words, paralanguage, movement, prossemics and touch. In the traditional hypnotic setting, like in real-life interactions, all these aspects are involved, but it is not clear if they are all essential to reach plastic monoideism. It is just natural to wonder if a physical and direct hypnotist $\leftrightarrow$ subject interaction is necessary in the transmission of hypnotic information, or on the contrary the message conveyed is what really matters.

Given the importance of voice in some of the theories about the nature of hypnosis itself (Jaynes, 1976), it made sense to try to induce and maintain hypnosis with words only. To this aim, we decided to employ radio transmission of voice, shifting the hypnotist in a different and separate room. The basis of this way to proceed was the belief that the active and voluntary involvement of the subject and the relationship of confidence and trust between the hypnotist and the subject would remain the fundamental principles of hypnotic experience. What changed was only how hypnotist and subject were in contact. It is important to remember that this kind of communication is not one-sided: the transmitter-receiver allowed the subject to give a feedback on his state of relaxation and well-being and to guide the hypnotist in the induction and management of the experience.

As a matter of fact, all subjects reached a comparable degree of hypnosis both in the presence of the hypnotist and through radio communication, reporting no significant difference between the two procedures. Times of permanence in icy 
water, higher during HFA than in usual consciousness condition, were also similar in HFA-P and HFA-R, and the reflex response to pain was comparable too, confirming that, as in our previous experience (Casiglia et al., 2007, 2015, 2016; Facco et al., 2011), HFA is due to a real block of painful stimuli.

Strength of this study is that it adopts instruments from cardiovascular research, applying them to hypnosis. This allowed adding objectively measurable outcomes-such as the duration of the $\mathrm{CPT}$ and the hemodynamic response to pain-to the subjective evaluation of efficacy presented by the previous studies in this field (Stanton, 1978; Roberts, 1978; Gravitz, 1983; Cooperman \& Schafer, 1983; Owens, 1970; Van Nuys, 1977).

Limitations are the little number of subjects and the fact that they were all highs who had already undergone sessions of hypnosis. It is evident that the number of participants is too small to be considered as representative of general population. This is in the pilot nature of the study. On the other hand, positive and significant results were obtained, making $\beta$-error implausible.

In conclusion, in our experience HFA-R turned out to be equivalent to HFA-P both in the subjective experience of the participants and in the objective results. Information can travel and reach its destination without being altered or lessened by the interposition of space or of a device between who sends and who receives it; hypnotic message per se is more important than the mean chosen to transmit it.

If the results of this pilot study will be confirmed on a larger scale and with subjects not already accustomed to hypnosis, the future applications of this new approach to hypnotic communication are many, i.e. pain medicine, disaster medicine or the management of situations in which subjects who can benefit from hypnosis cannot be reached directly or fast enough.

All authors declare no conflict of interest. All authors took part in the preparation of the manuscript, read it and approved its submission.

\section{References}

Beevi, Z., Low, W. Y., \& Hassan, J. (2017). The Effectiveness of Hypnosis Intervention for Labor: An Experimental Study. American Journal of Clinical Hypnosis, 60, 172-191. https://doi.org/10.1080/00029157.2017.1280659

Butcher, J. N., \& Williams, C. L. (1989). Fondamenti per l interpretazione del MMPI-2 e del PI- $A$. Firenze: Organizzazioni Speciali Giunti.

Cooperman, S., \& Schafer, D. W. (1983). Hypnotherapy over the Telephone. American Journal of Clinical Hypnosis, 25, 277-279. https://doi.org/10.1080/00029157.1983.10404115

Casiglia, E. (Ed.) (2015). Trattato d'ipnosi e altre modificazioni di coscienza. Padova: CLEUP.

Casiglia, E., Mazza, A., Ginocchio, G., Onesto, C., Pessina, A.C., Rossi, A., Marotti, A., et al. (1997). Haemodynamics Following Real and Hypnosis-Simulated Phlebotomy. American Journal of Clinical Hypnosis, 40, 368-375. https://doi.org/10.1080/00029157.1997.10403405 
Casiglia, E., Rempelou, P., Tikhonoff, V., Giacomello, M., Finatti, F., Albertini, F., Facco, E., et al. (2016). Hypnotic Focused Analgesia Obtained through Body Dysmorphism Prevents Both Pain and Its Cardiovascular Effects. Sleep and Hypnosis, 19, 89-95. https://doi.org/10.5350/Sleep.Hypn.2016.18.0127

Casiglia, E., Rempelou, P., Tikhonoff, V., Guidotti, F., Pergher, V., Giordano, N., Facco, E., et al. (2015). Hypnotic General Anesthesia vs. Focused Analgesia in Preventing Pain and Its Cardiovascular Effects. ATINER' S Conference Paper Series, INM2015-1638.

Casiglia, E., Rossi, A., Tikhonoff, V., Scarpa, R., Tibaldeschi, G., Giacomello, M., Lapenta, A. M., et al. (2006). Local and Systemic Vasodilation Following Hypnotic Suggestion of Warm Tub Bathing. International Journal of Psychophysiology, 62, 60-65. https://doi.org/10.1016/j.ijpsycho.2006.01.012

Casiglia, E., Schiavon, L., Tikhonoff, V., Haxhi Nasto, H., Azzi, M., Rempelou, P., Rossi, A. M., et al. (2007). Hypnosis Prevents the Cardiovascular Response to Cold Pressor Test. American Journal of Clinical Hypnosis, 49, 255-266. https://doi.org/10.1080/00029157.2007.10524503

Casiglia, E., Schiff, S., Facco, E., Gabbana, A., Tikhonoff, V., Schiavon, L., Amodio, P., et al. (2010). Neurophysiological Correlates of Post-Hypnotic Alexia. A Controlled Study with Stroop Test. American Journal of Clinical Hypnosis, 52, 219-233. https://doi.org/10.1080/00029157.2010.10401721

Casiglia, E., Tikhonoff, V., Giordano, N., Andreatta, E., Regaldo, G., Tosello, M.T., Facco, E., et al. (2012). Measured Outcomes with Hypnosis as an Experimental Tool in a Cardiovascular Physiology Laboratory. International Journal of Clinical and Experimental Hypnosis, 60, 241-261. https://doi.org/10.1080/00207144.2012.648078

Casiglia, E., Tikhonoff, V., Giordano, N., Regaldo, G., Facco, E., Marchetti, P., Amodio, P., et al. (2012). Relaxation versus Fractionation as Hypnotic Deepening: Do They Differ in Physiological Changes? International Journal of Clinical and Experimental Hypnosis, 60, 241-261. https://doi.org/10.1080/00207144.2012.648078

Chaves, J. F., \& Dworkin, S. F. (1997). Hypnotic Control of Pain: Historical Perspectives and Future Prospects. International Journal of Clinical and Experimental Hypnosis, 45, 356-376. https://doi.org/10.1080/00207149708416138

Demertzi, A., Soddu, A., Faymonville, M. E., Bahri, M. A., Gosseries, O., Vanhaudenhuyse, A., Laureys, S., et al. (2011). Hypnotic Modulation of Resting State fMRI Default Mode and Extrinsic Network Connectivity. Progress in Brain Research, 193, 309-322. https://doi.org/10.1016/B978-0-444-53839-0.00020-X

De Pascalis, V., Russo, O., \& Marrucci, F. S. (2000). Italian Norms for the Harvard Group Scale of Hypnotic Susceptibility, Form A. International Journal of Clinical and Experimental Hypnosis, 48, 44-55. https://doi.org/10.1080/00207140008410360

Douglas, P. K., Pisani, M., Reid, R., Head, A., Lau, E., Mirakhor, E., \& Cohen, M. S. (2014). Method for Simultaneous fMRI/EEG Data Collection during a Focused Attention Suggestion for Differential Thermal Sensation. Journal of Visualized Experiments, No. 83, e3298. https://doi.org/10.3791/3298

Du Bois, D., \& Du Bois, E. F. (1926). A Formula to Estimate the Approximate Surface area if Height and Weight Be Known. Archives of Internal Medicine, 17, 863-871.

Facco, E., Casiglia, E., Masiero, S., Tikhonoff, V., Giacomello, M., \& Zanette, G. (2011). Effects of Hypnotic Focused Analgesia on Dental Pain Threshold. International Journal of Clinical and Experimental Hypnosis, 59, 454-468.

https://doi.org/10.1080/00207144.2011.594749

Giordano, N., Tikhonoff, V., Tosello, M. T., Lapenta, A. M., \& Casiglia, E. (2012). An Experimental Approach to Hypnotic Age Regression: Controlled Study over 10 Healthy Participants. Contemporary Hypnosis \& Integrative Therapy, 29, 271-283. 
Granone, F. (1972). Trattato di ipnosi. Torino: UTET.

Gravitz, M. A. (1983). Early Use of the Telephone and Recordings in Hypnosis. American Journal of Clinical Hypnosis, 25, 280-282. https://doi.org/10.1080/00029157.1983.10404116

Griffiths, M. J. (2017). The Role of Hypnotherapy in Evidence-Based Clinical Practice. Oral Diseases, 23, 420-423. https://doi.org/10.1111/odi.12532

Hathaway, S. R., \& McKinley, J. C. (1985). Minnesota Multiphasic Personality Inventory 2 Manual. Firenze: Organizzazioni Speciali Giunti.

Häuser, W., Hagl, M., Schmierer, A., \& Hansen, E. (2016). The Efficacy, Safety and Applications of Medical Hypnosis. A Systematic Review of Meta-Analyses. Deutsches Ärteblatt International, 113, 289-296.

Hosseinzadegan, F., Radfar, M., Shafiee-Kandjani, A. R., \& Sheikh, N. (2017). Efficacy of Self-Hypnosis in Pain Management in Female Patients with Multiple Sclerosis. International Journal of Clinical and Experimental Hypnosis, 65, 86-97. https://doi.org/10.1080/00207144.2017.1246878

International Database on Ambulatory Blood Pressure in Relation to Cardiovascular Outcomes (IDACO) Investigators (2013). Double Product Reflects the Predictive Power of Systolic Pressure in the General Population: Evidence from 9,937 Participants. American Journal of Hypertension, 26, 665-672.

Iserson, K. V. (2014). An Hypnotic Suggestion: Review of Hypnosis for Clinical Emergency Care. Journal of Emergency Medicine, 46, 588-596.

https://doi.org/10.1016/j.jemermed.2013.09.024

Jaynes, J. (1976). The Origin of Consciousness in the Breakdown of the Bicameral Mind. Boston, MA: Houghton Mifflin.

Landry, M., Lifshitz, M., \& Raz, A. (2017). Brain Correlates of Hypnosis: A Systematic Review and Meta-Analytic Exploration. Neuroscience \& Biobehavioral Review, 81, 75-98. https://doi.org/10.1016/j.neubiorev.2017.02.020

McGeown, W. J., Mazzoni, G., Vannucci, M., \& Venneri, A. (2015). Structural and Functional Correlates of Hypnotic Depth and Suggestibility. Psychiatry Research, 231, 151-159. https://doi.org/10.1016/j.pscychresns.2014.11.015

Mitchell, L. A., MacDonald, R. A. R., \& Brodie, E. E. (2004). Temperature and the Cold Pressor Test. Journal of Pain, 5, 233-238. https://doi.org/10.1016/j.jpain.2004.03.004

Müller, K., Bachta, K., Schrammb, S., \& Seitza, R. J. (2012). The Facilitating Effect of Clinical Hypnosis on Motor Imagery: An fMRI Study. Behavioural Brain Research, 231, 164-169. https://doi.org/10.1016/j.bbr.2012.03.013

Owens, H. E. (1970). Hypnosis by Phone. American Journal of Clinical Hypnosis, 13, 57-60. https://doi.org/10.1080/00029157.1970.10402078

Peckerman, A., Saab, P. G., Llabre, M. M., Hurwitz, B. E., McCabe, P. M., \& Schneiderman, N. (1998). Cardiovascular and Perceptual Effects of Reporting Pain during the Foot and Forehead Cold Pressor Tests. International Journal of Behavioral Medicine, 5, 106-117. https://doi.org/10.1207/s15327558ijbm0502_2

Raz, A., Fan, J., \& Posner, M. I. (2005). Hypnotic Suggestion Reduces Conflict in the Human Brain. Proceedings of the National Academy of Sciences of the USA, 102, 9978-9983. https://doi.org/10.1073/pnas.0503064102

Roberts, J. A. (1978) Hypnosis by Telephone. Medical Journal of Australia, 2, 158-160.

Sevre, K., \& Rostrup, M. (1999). Blood Pressure and Heart Rate Responses to Cold Pressor Test in Patients Admitted to Hospital Due to Chest Pain. Blood Pressure, 8, 110-113. https://doi.org/10.1080/080370599438284 
Sharav, Y., \& Tal, M. (2004). Focused Analgesia and Generalized Relaxation Produce Differential Hypnotic Analgesia in Response to Ascending Stimulus Intensity. International Journal of Psychophysiology, 52, 187-196.

https://doi.org/10.1016/j.ijpsycho.2003.10.001

Shor, R. E., \& Orne, E. C. (1963). Norms on the Harvard Group Scale of Hypnotic Susceptibility, form A. International Journal of Clinical and Experimental Hypnosis, 11, 39-47. https://doi.org/10.1080/00207146308409226

Stanton, H. E. (1978). Hypnotherapy at a Distance through Use of the Telephone. American Journal of Clinical Hypnosis, 20, 278-281. https://doi.org/10.1080/00029157.1978.10403945

Stewart, J. H. (2005). Hypnosis in Contemporary Medicine. Mayo Clinic Proceedings, 80, 511-524. https://doi.org/10.4065/80.4.511

Tikhonoff, V., Azzi, D., Boschetti, G., Giordano, N., Rempelou, P., Giacomello, M., \& Casiglia, E. (2012). Increase of Isometric Performance via Hypnotic Suggestion: Experimental Study over 10 Young Healthy Volunteers. Contemporary Hypnosis \& Integrative Therapy, 29, 352-362.

Tikhonoff, V., Senzolo, M., Lapenta, A. M., Palatini, P., \& Casiglia, E. (2017). Hypnotic Hallucination of Body Heating Modifies Splanchnic Circulation: Haemodynamic and Ultrasonographic Pilot Study in Normal Volunteers. Sleep and Hypnosis. https://doi.org/10.5350/Sleep.Hypn.2017.19.0132

Van Nuys, D. (1977). Successful Treatment of Sacroiliac Pain by Telephone. A Brief Clinical Report. Journal of the American Society of Psychosomatic Dentistry and Medicine, 24, 73-75.

White, W. B. (1999). Heart Rate and the Rate-Pressure Product as Determinants of Cardiovascular Risk in Patients with Hypertension. American Journal of Hypertension, 12, 50s-55s. https://doi.org/10.1016/S0895-7061(98)00280-5 